\title{
NEUROTROPHIC REGULATION OF THE PHOSPHORYLATION OF A SOLUBLE CYTOSOLIC PROTEIN IN SKELETAL MUSCLE ${ }^{1}$
}

\author{
IRENE R. HELD, ${ }^{2}$ STEPHEN P. SQUINTO, AND JERRY A. MCLANE \\ Neuroscience Research Laboratory, Veterans Administration Hospital, Hines, Illinois 60141 and Departments of Biochemistry \\ and Pharmacology, Loyola University, Stritch School of Medicine, Maywood, Illinois 60153
}

Received February 28, 1983; Revised May 2, 1983; Accepted May 5, 1983

\begin{abstract}
Neural influences are exerted not only by propagation of nerve impulses, but also by trophic actions of the motor neuron upon its contiguous muscle cell. Previously, we found that the in vitro phosphorylation of soluble protein catalyzed by an endogenous protein kinase is increased in cytosolic fractions from denervated soleus muscles. This alteration occurred within several hours after the loss of some neural influence, but not as an immediate consequence of denervation (Squinto, S. P., J. A. McLane, and I. R. Held (1980) Neurosci. Lett. 20: 295-300; Squinto, S. P., J. A. McLane, and I. R. Held (1981) Neurochem. Res. 6: 203-211). In this paper, we further define the cytosolic protein substrates and demonstrate a nerve stump length-dependent phosphorylative modulation of the predominate substrate in rat soleus muscles which were denervated for 1,3 , and $6 \mathrm{hr}$ and then at 6 -hr intervals to $78 \mathrm{hr}$ by unilaterally cutting the sciatic nerve to leave either a short (2 $\mathrm{mm}$ or less), intermediate $(17$ to $20 \mathrm{~mm}$ ), or long (32 to $35 \mathrm{~mm}$ ) distal nerve stump attached to the muscle. The results are compared with those obtained from sham-operated, contralateral solei and unoperated muscles.

We found that the times of onset and of maximal increase of the in vitro phosphorylation of soluble cytosolic protein in denervated solei are directly related to the lengths of the distal nerve stumps; i.e., $1.4 \mathrm{hr} / \mathrm{mm}$ and $1.3 \mathrm{hr} / \mathrm{mm}$, respectively, based upon linear regression analysis. Also, this alteration could be accounted for by an increased phosphorylation of a 56-kilodalton soluble cytosolic protein which was resolved as a minor protein-staining band after SDS slab PAGE. Although gel autoradiographs clearly showed that other soluble cytosolic proteins were also phosphorylated, $\sim 80 \%$ of the incorporated ${ }^{32} \mathrm{P}$ label was bound to the 56-kilodalton substrate. The transfer of ${ }^{32} \mathrm{PO}_{4}$ from $\left[\gamma_{-}{ }^{32} \mathrm{P}\right] \mathrm{ATP}$ to the 56 -kilodalton protein during the assay was markedly inhibited by cAMP, but was not affected by $\mathrm{Ca}^{2+}$, cGMP, or a specific inhibitor of cAMP-dependent protein kinase. The possibility that the 56 -kilodalton protein substrate is the autophosphorylatable regulatory subunit of protein kinase type II is discussed. The temporal relationship of the increased phosphorylation of the 56-kilodalton protein with the denervation period and nerve stump length suggests this change is mediated by some neurotrophic regulation of skeletal muscle.
\end{abstract}

Motor neurons influence the muscle cells that they innervate not only by regulation of contractile activity through the impulse-directed release of acetylcholine (ACh) (Buller et al., 1960; Close, 1972), but also through neurotrophic functions by the spontaneous release of ACh (Drachman et al., 1982) and other unidentified factors (Harris, 1974, 1980; Gutmann, 1976; Guth and

${ }^{1}$ This work was supported by National Institutes of Health Grant NS-11755, by the Medical Research Service of the Veterans Administration, and by a Biomedical Research support grant from Loyola University Stritch School of Medicine. We wish to thank Hock C. Yeoh for his excellent technical assistance.

${ }^{2}$ To whom correspondence should be addressed.
Albuquerque, 1979). Putative neurotrophic factors are thought to be provided from their sites of synthesis in neuronal perikarya to the neuromuscular junction by means of the fast axoplasmic transport system (Ochs, 1974; Lubinska, 1975; Grafstein and Forman, 1980). Following denervation, therefore, the supply of an axonally transported neurotrophic mediator will be limited quantitatively and temporally by the length of the distal nerve stump left attached to the muscle. But since the impulsedirected usage of skeletal muscle ceases with any level of transection of the innervating motor fibers, the roles played by neurotrophic influences and muscle contractile activity per se can be differentiated by determining whether there is a direct temporal relationship between 
a denervation effect and the length of the distal nerve stump.

Early effects of denervation which occur before muscle atrophy have been of interest to us, particularly those potentially relevant to the synthesis of muscle proteins, because these changes may reflect metabolic events which mediate neurotrophic influences. We have found that the rate of gene transcription by nuclear RN $\Lambda$ polymerases is increased in nuclei isolated from skeletal muscle within a 2-day denervation period (Held, 1978). Concomitantly, the in vitro phosphorylation of endogenous nuclear proteins is increased (Held, 1983). Other investigators have reported that the activation of these nuclear events in a variety of nonmuscle cells is mediated by the translocation of cytosolic cAMP-dependent protein kinase to the nucleus (reviewed by Sharma, 1982). When we evaluated the endogenous protein kinase (ATP:protein phosphotransferase EC 2.7.1.37)-catalyzed phosphorylation of soluble cytosolic protein in denervated muscles, a marked increase was found to occur after a latent period of a few hours (Squinto et al., 1980, 1981).

In this investigation, a nerve stump length protocol was employed to determine whether an alteration of neural factors other than those associated with the impulse-directed release of $\mathrm{ACh}$ is temporally related to the stimulation of cytosolic protein phosphorylation in denervated skeletal muscle. Additionally, we attempted to gain further insight into the metabolic significance and specificity of this reaction by resolution of the phosphorylated substrates with SDS slab PAGE and autoradiography. The nerve stump length paradigm has been used by other investigators (see "Discussion") to show the dependency of certain biochemical and electrophysiological parameters upon neurotrophic influences, but to our knowledge not with respect to the phosphorylation of muscle protein.

The results reported here demonstrate that the increased in vitro phosphorylation of a cAMP-modulated, 56 -kilodalton $(\mathrm{kd})$ soluble cytosolic protein after denervation of skeletal muscle is induced by some signal which is temporally related to the length of the distal nerve stump left attached to the muscle, but is independent of the loss of muscle contractile activity. Although other neuromuscular factors are not ruled out, the nerve stump length dependency of this phosphorylation event suggests the involvement of axonally transported neurotrophic substances.

Preliminary accounts of some of these findings have been reported (McLane et al., 1981, 1982).

\section{Materials and Methods}

Denervation surgery. Male Sprague-Dawley rats (3 months of age) obtained from King Animal Laboratories (Oregon, WI) were housed in groups of four or five with a 12-hr light/dark cycle and food and water ad libitum. The left soleus muscle was denervated while the animal was under light ether anesthesia by cutting the sciatic nerve in the midthigh region of the hindlimb leaving a 32- to $35-\mathrm{mm}$ distal nerve stump attached to the muscle. In other animals, after the midthigh cut was made, shorter nerve stumps were obtained by also cutting either the tibial branch of the sciatic nerve or the soleus branch of the tibial nerve to leave attached nerve stumps of 17 to $20 \mathrm{~mm}$ or $2 \mathrm{~mm}$, respectively. A sham operation was performed on the contralateral leg in every animal. Surgical preparations were carried out at appropriate times of day or night so that the animals were consistently sacrificed between 8 and 9 A.M. Groups of three rats were sacrificed by decapitation at 1,3 , and $6 \mathrm{hr}$ and then at 6 -hr intervals up to $78 \mathrm{hr}$ following these surgical procedures. Unoperated muscles were obtained from separate groups of animals.

Preparation of cytosolic fractions of the soleus muscle. The denervated and sham-operated soleus muscles were removed within several minutes after sacrifice of the animal and appropriately pooled in ice-cold homogenizing medium consisting of $0.32 \mathrm{M}$ sucrose and $3 \mathrm{mM} \mathrm{MgCl}$, $\mathrm{pH}$ 6.5. The muscles were freed of tendons and minced while on ice in a cold room. Then homogenization was carried out with a Virtis blade-type homogenizer in sufficient homogenizing medium to give a final muscle concentration of $2.5 \%(\mathrm{w} / \mathrm{v})$. This homogenate was vacuum filtered successively through 50,100 , and 150 mesh stainless steel screens. The supernatant recovered after centrifugation of the filtered homogenate at $900 \times \mathrm{g}$ and $4^{\circ} \mathrm{C}$ for $20 \mathrm{~min}$ was ultracentrifuged at $105,000 \times \mathrm{g}$ and $4^{\circ} \mathrm{C}$ for $45 \mathrm{~min}$ to obtain the cytosolic fraction. The concentration of soluble protein in this fraction was quantitated by the method of Lowry et al. (1951). The phosphorylation assay was always carried out with freshly prepared muscle cytosols.

Assay of cytosolic protein phosphorylation. This assay was performed as described previously (Squinto et al., 1980, 1981). The final concentrations of the components of the standard phosphorylating medium in a total volume of $0.25 \mathrm{ml}$ were as follows: $100 \mathrm{mM} \mathrm{NaCl}, 50 \mathrm{mM}$ Tris- $\mathrm{HCl}, \mathrm{pH} 7.5,2 \mathrm{mM} \mathrm{MgCl}$, and $6.7 \times 10^{-9} \mathrm{M}\left[\gamma^{32} \mathrm{P}\right]$ ATP $(3000 \mathrm{Ci} / \mathrm{mmol})$. The phosphotransferase reaction was started with the addition of an aliquot of the cytosolic fraction containing 15 to $90 \mu \mathrm{g}$ of soluble protein, which served as the source of the enzyme, and phosphorylatable substrate. In certain experiments (see "Results"), the final concentrations of additional components in the phosphorylation medium were as follows: $10^{-6} \mathrm{M}$ cAMP, $10^{-9}$ to $10^{-5} \mathrm{M}$ cGMP, $2 \times 10^{-8}$ to $10^{-3} \mathrm{M}$ $\mathrm{Ca}^{2+}$, or 50 inhibitory units of cAMP-dependent protein kinase inhibitor from bovine heart muscle (Sigma Chemical Co., St. Louis, MO) which was further purified prior to use essentially as described by Kanter and Brunton (1981). After an incubation period of $5 \mathrm{~min}$ at $37^{\circ} \mathrm{C}$, the reaction was stopped with cooling on ice and the addition of ATP and sodium pyrophosphate (NaPPi) to final concentrations of $0.33 \mathrm{~mm}$ and $1.3 \%$, respectively. Aliquots of the stopped reaction mixture were applied to Millipore filters (lype PH) which were washed extensively and kept overnight in $1.5 \% \mathrm{NaPPi}$ and $5 \%$ trichloroacetic acid. The precipitated ${ }^{32} \mathrm{P}$ radioactivity on these filters was assessed by liquid scintillation spectrometry. Cytosolic protein phosphorylation is expressed as the femtomoles of ${ }^{32} \mathrm{PO}_{4}$ incorporated per milligram of soluble protein per incubation period. The incorporation of ${ }^{32} \mathrm{PO}_{4}$ into protein-bound, alkali-labile, acid-stable phosphates was determined as described by Weller (1979). 
SDS slab PAGE. Aliquots of the stopped, in vilro cytosolic phosphorylation assay were prepared for slab PAGE by addition of sufficient SDS to make the final concentration $1.5 \%$ and heating in a boiling water bath for $2 \mathrm{~min}$. Then these treated, ${ }^{32} \mathrm{P}$-labeled proteins were dialyzed overnight against a 500-fold volume of electrophoresis buffer containing $0.0625 \mathrm{M}$ Tris- $\mathrm{HCl}, \mathrm{pH} 6.8$, $0.1 \%$ SDS, and 5\% 2-mercaptoethanol (Laemmli, 1970). Molecular weight marker proteins (Sigma Chemical Co.) for SDS-PAGE were prepared with heating in the same buffer. The treated proteins in aliquots of the dialyzed samples from denervated or sham-operated muscle were separated electrophoretically on $1.5-\mathrm{mm}$-thick SDS slab gels containing a 5 to $15 \%$ exponential acrylamide gradient in a double slab electrophoresis cell (Bio-Rad Laboratories, Richmond, CA). A stacking gel containing $4.5 \%$ acrylamide and $0.1 \%$ SDS was utilized. In those experiments in which the levels of ${ }^{32} \mathrm{P}$ labeling were being compared, special care was taken to load equivalent amounts of protein into the sample wells. Electrophoresis was carried out at $20 \mathrm{~mA} /$ gel while the sample was entering the stacking gel and then increased to $30 \mathrm{~mA} /$ gel until the tracking dye (bromphenol blue) had migrated into the running gel when the current was increased to $40 \mathrm{~mA} /$ gel. After the tracking dye had migrated $110 \mathrm{~mm}$, the gel was removed from between the glass plates for fixing overnight in a solution of methanol:acetic acid:water (5:1:5). Gels were stained with Coomassie brilliant blue $\mathrm{R}$ and destained first in the same methanol:acetic acid:water mixture, then in a 1:1:9 mixture of methanol:acetic acid:water, and finally overnight in $7 \%$ acetic acid containing $5 \%$ glycerol. The stained gels were dried on filter paper using a Bio-Rad gel drier and exposed to Kodak X-Omat AR film (Eastman Kodak Co., Rochester, NY) for 1 to 7 days to obtain an autoradiograph.

\section{Results}

Cytosolic protein phosphorylation in denervated soleus muscle. Assays were made of the endogenous phosphorylation of soluble protein in cytosolic fractions from rat soleus muscles that were denervated for 1,3 , and $6 \mathrm{hr}$, and then at 6-hr intervals to a maximum of $78 \mathrm{hr}$ by cutting the left sciatic nerve or its branch so that either a short nerve stump of $2 \mathrm{~mm}$ or less, an intermediate nerve stump of 17 to $20 \mathrm{~mm}$, or a long nerve stump of 32 to $35 \mathrm{~mm}$ was left attached to the muscle. The tibial or soleus branch of the sciatic nerve was cut to obtain the distal nerve stumps of intermediate or short nerve lengths, respectively. However, in these two experimental groups, as well as for the long nerve stump group, the sciatic nerve was also cut in the midthigh region at a distance of 32 to $35 \mathrm{~mm}$ from its insertion into the soleus. Consequently, the possibility of passive stretching of the soleus by contraction of neighboring muscles was similarly eliminated in all three animal groups.

In Figure 1, mean levels of cytosolic protein phosphorylation of denervated, sham-operated, and unoperated solei are presented. This activity was determined as the femtomoles of ${ }^{32} \mathrm{PO}_{4}$ incorporated into trichloroacetic acid-precipitable material per milligram of soluble cytosolic protein incubated for $5 \mathrm{~min}$ in a buffered phospho-

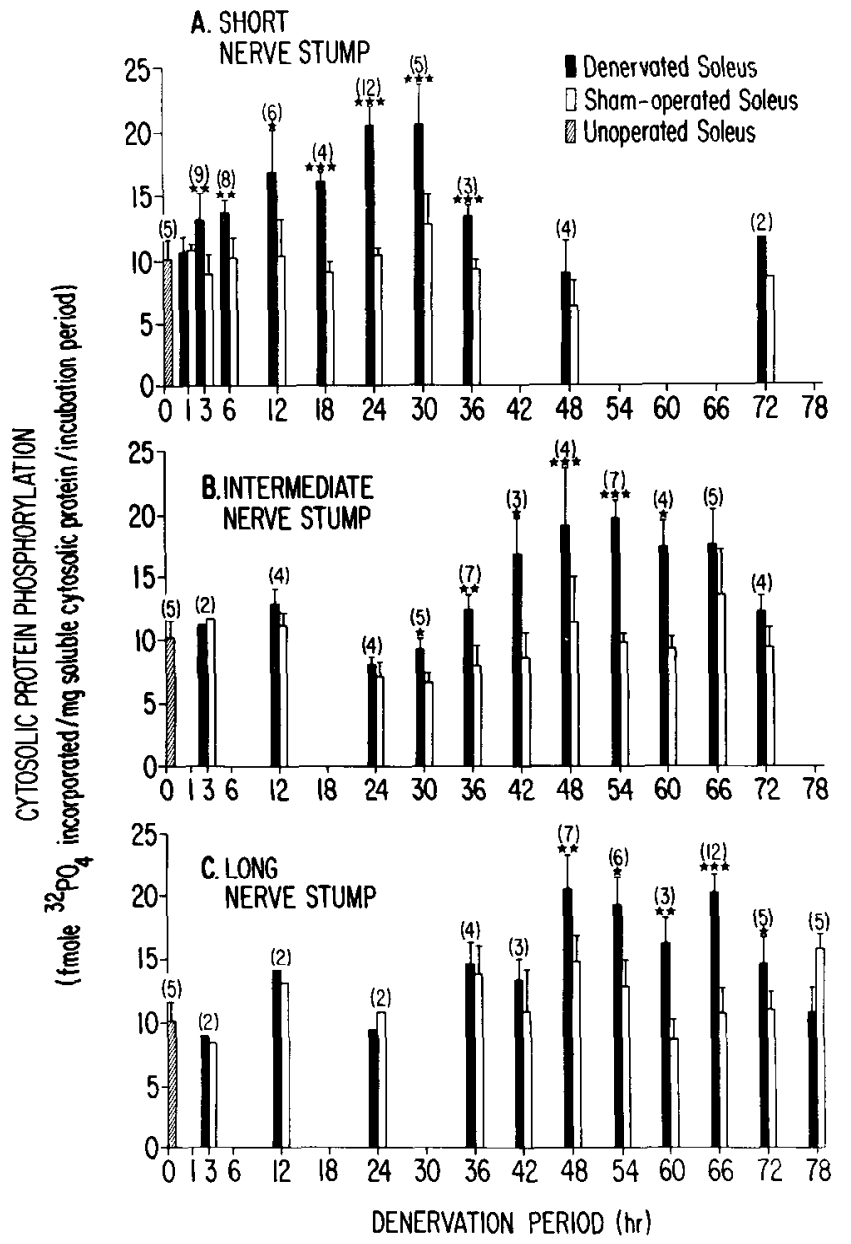

Figure 1. Temporal dependency of cytosolic protein phosphorylation of denervated soleus muscle upon the length of the distal nerve stump remaining attached to the muscle. The left soleus muscle of the rat hindlimb was denervated for the given periods prior to sacrifice by transecting the sciatic nerve or its branches so that the distal nerve stumps were $<2 \mathrm{~mm}(A), 17$ to $20 \mathrm{~mm}(B)$, or 32 to $35 \mathrm{~mm}(C)$. A sham operation was performed on the contralateral hindlimb. Unoperated muscles were obtained from separate groups of animals. Cytosolic protein phosphorylation was conducted as described under "Materials and Methods" in a solution containing $0.1 \mathrm{M} \mathrm{NaCl}, 50$ mM Tris- $\mathrm{HCl}, \boldsymbol{p H} 7.5,2 \mathrm{mM} \mathrm{MgCl}_{2}$, and $6.7 \times 10^{-9} \mathrm{M}\left[\gamma^{-{ }^{32}} \mathrm{P}\right]$ ATP $(3000 \mathrm{Ci} / \mathrm{mmol})$ in a total volume of $0.25 \mathrm{ml}$. The results are means $\pm \mathrm{SEM}$ for the number of groups of three rats indicated in parentheses. $*, p<0.05 ; * *, p<0.02 ; * * *, p<0.01$ based upon paired $t$ tests.

rylating medium ( $\mathrm{pH} 7.5$ ) containing $\mathrm{Mg}^{2+}$ and $\left[\gamma^{-32} \mathrm{P}\right]$ ATP. The soluble protein provided by the high speed supernatant of the soleus homogenate (cytosolic fraction) included endogenous protein kinases and phosphorylatable protein substrates. We have determined that most of the in vitro ${ }^{32} \mathrm{P}$ label associated with the cytosolic protein substrates of both denervated $(85.6 \pm$ $1.7 \%, n=3)$ and sham-operated $(84.1 \pm 2.0 \%, n=3)$ solei is incorporated as alkali-labile, acid-stable phosphate, probably linked to serine or threonine residues.

Figure 1 also shows that the level (2-fold) and period ( 24 to $33 \mathrm{hr}$ ) of stimulation of cytosolic protein phosphorylation were similar whether a short, intermediate, or 
long nerve stump was left attached to the muscle. However, the lapse of time after denervation of the soleus until the occurrence of a significant increase was different for each distal nerve stump. That is, while the phosphorylation of cytosolic protein was increased significantly after $3 \mathrm{hr}(p<0.02)$ when a short nerve stump (2 $\mathrm{mm}$ or less) remained, this was not observed until $30 \mathrm{hr}$ $(p<0.05)$ and $48 \mathrm{hr}(p<0.02)$ for the intermediate $(17$ to $20 \mathrm{~mm}$ ) and long ( 32 to $35 \mathrm{~mm}$ ) nerve stumps, respectively. The statistical evaluation of these results was based upon paired Student's $t$ tests; i.e., the level of cytosolic protein phosphorylation of each denervated soleus muscle was compared to that of the sham-operated soleus from the contralateral hindlimb. Since each animal served as its own control, minor variations in the levels of protein phosphorylation which were observed in sham-operated muscles from different animal groups are obviated. At earlier periods of 3,12 , and $24 \mathrm{hr}$ and of $3,12,24,36$, and $42 \mathrm{hr}$ for intermediate and long nerve stump-muscles, respectively, no significant differences between denervated and sham-operated muscles were observed. Also, cytosolic protein phosphorylation of muscles from unoperated animals did not differ significantly from that of these sham-operated muscles.

Relation of times of onset and of maximal increase of cytosolic protein phosphorylation following denervation to the length of the distal nerve stump. As seen in Figure 2, the onset of increased phosphorylation of soluble cytosolic protein relates directly to the length of the distal nerve stump left attached to the soleus muscle; i.e., the delay in occurrence of this event is $1.4 \mathrm{hr} / \mathrm{mm}$ of nerve based upon the three different nerve stump lengths. Onset was taken as the earliest denervation period shown in Figure 1 at which the increase in cytosolic protein phosphorylation was significant with $p<0.05$. Our estimate of the onset of this event is limited by the interval between the denervation periods. Whereas this was only $2 \mathrm{hr}$ for the short nerve stump, the interval was $6 \mathrm{hr}$ for the studies with intermediate and long nerve stumps. Also, our measurements of the lengths of the distal nerve stumps do not include those of intramuscular nerves.

Additionally, the linear regression line in Figure 2, which is based upon the denervation period at which the greatest increase of cytosolic protein phosphorylation relative to sham-operated muscles was observed, also indicates that this change is directly related to the nerve slump length and is delayed $1.3 \mathrm{hr}$ for each millimeter of nerve remaining attached to the muscle. The denervation period with maximal increase in phosphorylation occurred at 24,54, and $66 \mathrm{hr}$ for muscles with distal nerve stumps of $<2 \mathrm{~mm}, 17$ to $20 \mathrm{~mm}$, and 32 to $35 \mathrm{~mm}$, respectively, as shown in Figure 1.

Effect of denervation upon soleus muscle weight. In Table I are listed the wet weights of the soleus muscles used to obtain the phosphorylation results at certain denervation periods shown in Figure 1. It can be seen that the maximal increase of cytosolic protein phospho-

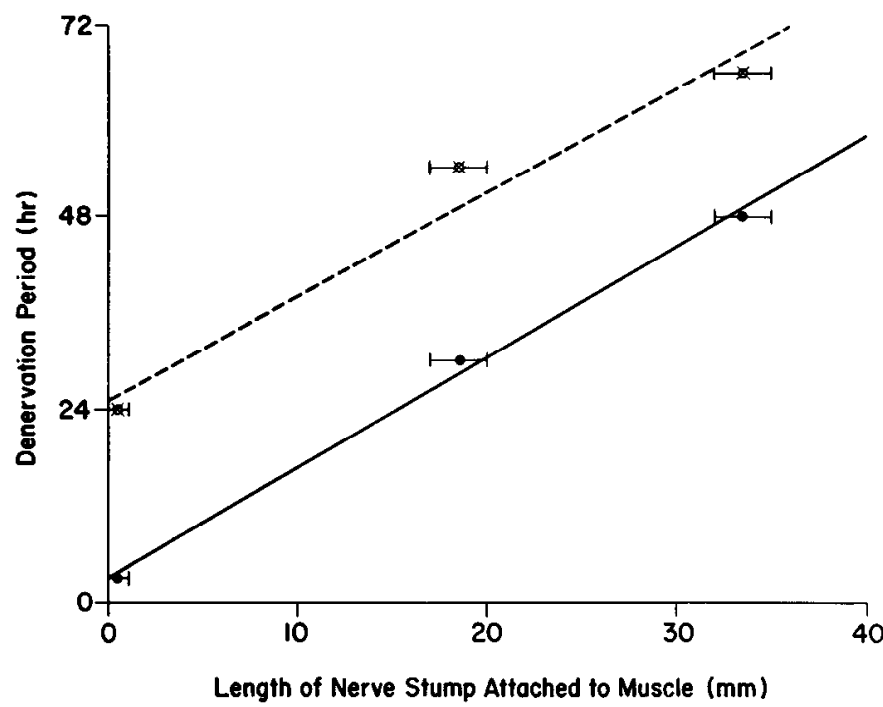

Figure 2. The relationship of the times of onset and of maximal increase of cytosolic protein phosphorylation in denervated solei to the length of the nerve stump left attached to the muscle. Time of onset was defined as the time at which increased protein phosphorylation was first statistically significant $(p<0.05)$. As shown in Figure 1 , this occurred at 3,30 , and $48 \mathrm{hr}$ for muscles with distal nerve stumps of $<2 \mathrm{~mm}, 17$ to $20 \mathrm{~mm}$, and 32 to $35 \mathrm{~mm}$, respectively. The slope of the solid linear regression line derived from these points indicates that the onset of increased protein phosphorylation is delayed 1.4 $\mathrm{hr}$ for each millimeter of nerve left attached to the muscle. The time of maximal increase as shown in Figure 1 occurred at 24, 54 , and $66 \mathrm{hr}$ for muscles with distal nerve stumps of $<2 \mathrm{~mm}$, 17 to $20 \mathrm{~mm}$, and 32 to $35 \mathrm{~mm}$, respectively. The dashed linear regression line derived from these points indicates that the maximal increase is delayed for $1.3 \mathrm{hr}$ for each millimeter of nerve left attached to the muscle.

TABLE I

Comparison of denervated and sham-operated soleus muscle weight"

\begin{tabular}{|c|c|c|c|c|c|c|}
\hline Period (hr) & \multicolumn{2}{|c|}{ Short Nerve Stump } & \multicolumn{2}{|c|}{ Intermediate Nerve Stump } & \multicolumn{2}{|c|}{ Long Nerve Stump } \\
\hline $\begin{array}{c}\text { Denervated }(t) \text { or } \\
\text { sham-operated }(-)\end{array}$ & - & + & - & + & - & + \\
\hline 24 & $0.49 \pm 0.05$ & $0.49 \pm 0.08^{b}$ & $0.43 \pm 0.04$ & $0.42 \pm 0.01$ & & \\
\hline 54 & & & $0.42 \pm 0.01$ & $0.42 \pm 0.02^{b}$ & $0.49 \pm 0.02$ & $0.39 \pm 0.02^{b}$ \\
\hline 66 & & & $0.40 \pm 0.01$ & $0.38 \pm 0.01^{c}$ & $0.43 \pm 0.01$ & $0.40 \pm 0.01^{b, c}$ \\
\hline
\end{tabular}

${ }^{a}$ Means \pm SEM of wet weight (grams) for three pooled muscles of the same groups of rats indicated in Figure 1. The values for the unoperated muscles were $0.44 \pm 0.03$.

${ }^{b}$ Indicates the denervation period when a significant increase of cytosolic protein phosphorylation compared to the level of the sham-operated muscles was found.

"Indicates the weight of the pooled denervated soleus was significantly less $(p<0.01)$ than that of the muscle from the sham-operated, contralateral hindlimbs based upon paired $t$ tests. 
rylation (see Fig. 1 and Footnote $b$ in Table I) appears well before there is a significant loss of muscle weight (see Footnote $c$ in Table I). In addition, although there is significant atrophy $(p<0.01)$ for the $66-\mathrm{hr}$ denervated soleus with either the intermediate or long nerve stumps, still protein phosphorylation is increased $(p<0.01)$ for the latter group.

Resolution of the denervation period and nerve stump length-dependent soluble cytosolic phosphoprotein. After the soleus cytosols had been incubated in the $\left[\gamma^{32} \mathrm{P}\right]$ ATP-phosphorylating medium, treated with SDS, and dialyzed, the protein components were then resolved by electrophoresis using the Laemmli (1970) slab gel system with a 5 to $15 \%$ exponential polyacrylamide gradient
(Fig. 3). With this gel system, we have been able to reproducibly resolve 45 Commassie blue-staining protein bands (Fig. $3 B$ ). Autoradiography of the dried slab gels clearly revealed 10 bands of protein which were phosphorylated during the in vitro assay (Fig. $3, C$ to $H$ ). However, based upon liquid scintillation counting of 2mm gel sections, $\sim 80 \%$ of the incorporated radioactivity was associated with a minor protein-staining band. This predominant ${ }^{32} \mathrm{P}$-labeled protein had a relative $M_{\mathrm{r}}$ in this gel system of 56,000 (Fig. $3, C$ to $H$ ). The relative molecular weights of the nine other radiolabeled proteins producing a less intense autoradiographic image are indicated in Figure $3 C$. The low levels of ${ }^{32} \mathrm{P}$ radioactivity in these bands, revealed by autoradiography in which only

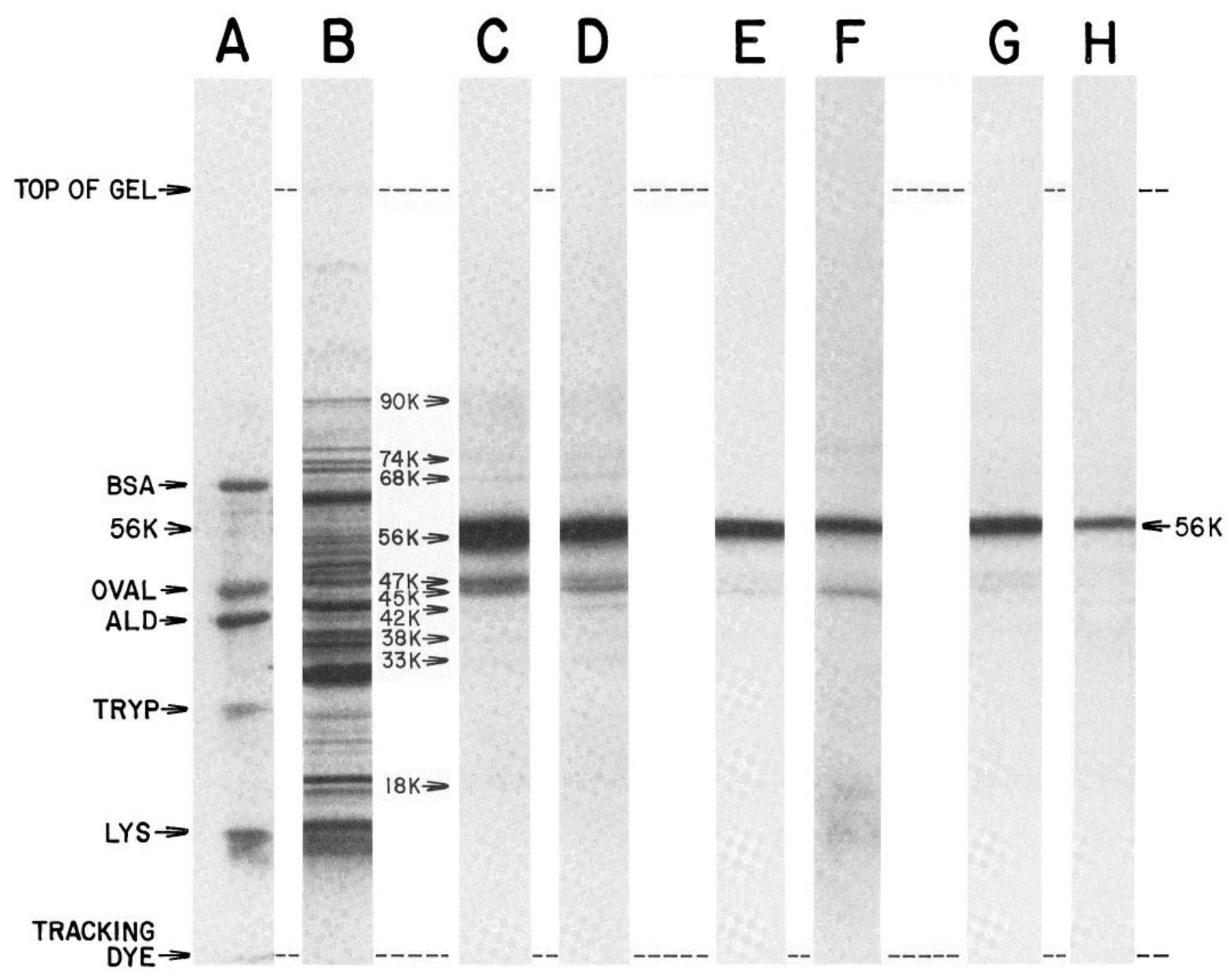

Figure 3. Resolution of the denervation period and nerve stump length-dependent phosphoprotein from soleus muscle cytosol by SDS slab PAGE. ${ }^{32}$ P-radiolabeled cytosol samples of denervation periods for each distal nerve stump length when protein phosphorylation was maximally increased were prepared for electrophoresis as described under "Materials and Methods." A representative gel of the reproducible Coomassie blue staining pattern is shown $(B)$. Autoradiographs of the resolved cytosolic samples from muscles denervated for $24 \mathrm{hr}$ with a short stump $(C), 54 \mathrm{hr}$ with an intermediate stump $(E)$, or $66 \mathrm{hr}$ with a long stump $(G)$ are shown along with their respective contralateral, sham-operated controls $(D, F$, and $H)$. Molecular weights of proteins in the radiolabeled bands $(C)$ were determined relative to the mobilities of proteins of known molecular weight $(A)$. These standard proteins (and their molecular weights) are as follows: BSA, bovine serum albumin (66K); $O V A L$, ovalbumin (45K); $A L D$, aldolase subunit (40K); TRYP, trypsinogen (24K); and $L Y S$, lysozyme (14.3K). 
$\sim 20 \%$ of the total counts (usually 1500 to $2000 \mathrm{cpm}$ ) applied to the gel were distributed, prevented reliable quantitative assessment by liquid scintillation spectrometry.

When radiolabeled cytosol samples from denervated muscles showing maximal increases in cytosolic protein phosphorylation are resolved on these slab gels, an increased phosphorylation of the predominant $56-\mathrm{kd}$ phosphoprotein is very evident on the autoradiographs. However, denervation had no effect upon the protein staining pattern. In Figure 3, compare the autoradiographic density of the major ${ }^{32} \mathrm{P}$ band for soleus muscles denervated by leaving short (Fig. $3, C$ to $D$ ), intermediate (Fig. $3, E$ to $F$ ), or long (Fig. 3, $G$ to $H$ ) nerve stumps versus the ${ }^{32} \mathrm{P}$ density for the respective, sham-operated soleus. This consistently shows that there is a predominant increase in the phosphorylation of the 56-kd protein whenever the maximal increase in cytosolic protein phosphorylation was reached; i.e., at 24-, 54-, and 66-hr denervation periods for the short, intermediate, and long nerve stumps, respectively (see Fig. 1). It is pertinent to note that the density of the autoradiographs of one pair of samples cannot be compared with another pair since the half-life of ${ }^{32} \mathrm{P}$ is relatively short and the samples for the three pairs of denervated and sham-operated muscles were not available for electrophoresis simultaneously.

The relationship between the stimulation of the cytosolic protein phosphorylation and increased phosphorylation of the 56-kd phosphoprotein resolved by slab PAGE was also studied during the course of development of these changes in a short nerve stump muscle. When the cytosolic protein phosphorylation was significantly increased at $3,6,12,18$, and $24 \mathrm{hr}$ in the $2-\mathrm{mm}$ nerve stump muscle, then the ${ }^{32} \mathrm{P}$ radiolabeling of the $56-\mathrm{kd}$ band was also comparably increased; i.e., the percentage change for both of these parameters relative to the respective sham-operated, contralateral muscle was similar at any of these denervation periods as shown in Figure 4.

Effect of modulatory factors. If the concentration of an endogenous modulator of the cytosolic protein phosphorylation in either denervated or sham-operated cytosols is altered, then the activity of combined aliquots of these samples will deviate from the expected additive value derived from results of assays of these samples separately. When equal aliquots of cytosols from a 24-hr short nerve stump-muscle and from the contralateral muscle were assayed, cytosolic protein phosphorylation was significantly $(p<0.01)$ decreased by $9.4 \pm 2.1 \%$ ( $n$ $=8$ ) from the expected value. This result suggests that the concentration of a negative modulator of the phosphorylation reaction is relatively higher in the shamoperated compared to the denervated cytosol.

The effect of potential, specific modulators upon the ${ }^{32} \mathrm{P}$ labeling of the 56 -kd phosphoprotein was then evaluated. In Figure 5, the autoradiographs from SDSPAGE-resolved soluble cytosolic proteins from 24-hr denervated short nerve stump solei and sham-operated, contralateral solei show that the level of phosphorylation of the $56-\mathrm{kd}$ band in both samples is almost completely inhibited by the addition of $10^{-6}$ M cAMP to the phosphorylation medium. Quantitatively, the radiolabeling of

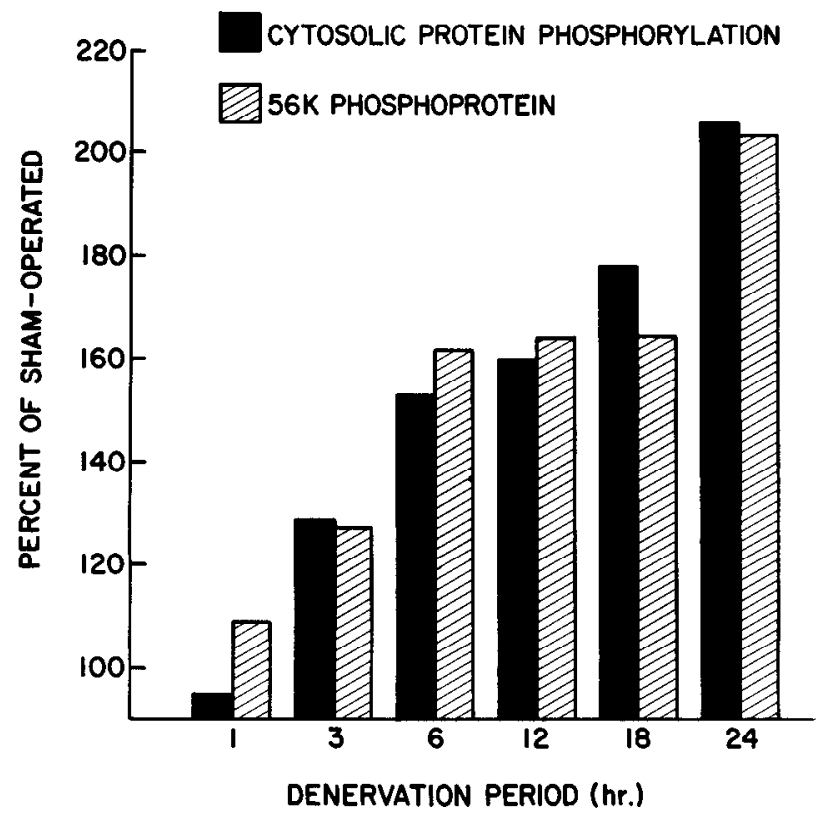

Figure 4. The relationship between increased phosphorylation in denervated solei of soluble cytosolic protein (solid bars) and of a 56 -kd phosphoprotein resolved from this fraction (hatched bars). The levels of protein phosphorylation in denervated muscles are shown as the percentage of that in the contralateral, sham-operated muscles. The phosphorylation of soluble protein in cytosol samples from soleus muscles denervated with a short $(<2 \mathrm{~mm})$ nerve stump for periods of $1,3,6$, 12,18 , and $24 \mathrm{hr}$ was determined as described in Figure 1 in an aliquot from the assay solution. Also, the ${ }^{32} \mathrm{P}$ labeling of the 56$\mathrm{kd}$ protein resolved from a second aliquot by SDS slab PAGE was quantitated by liquid scintillation spectrometry. The region of the gel containing the 56-kd phosphoprotein was located by autoradiography and the relative radiolabeling calculated with respect to the amount of protein loaded onto the gel.

these gel slices determined by liquid scintillation spectometry was reduced $\sim 80 \%$. However, 50 units of the specific inhibitor of cAMP-dependent protein kinase (Ashby and Walsh, 1972) had little effect $(<18 \%)$ on the ${ }^{32} \mathrm{P}$ labeling of the $56-\mathrm{kd}$ band. In agreement with previous findings, $\mathrm{Ca}^{2+}\left(2 \times 10^{-8}\right.$ to $\left.10^{-3} \mathrm{M}\right)$ and cGMP $\left(10^{-9}\right.$ to $\left.10^{-5} \mathrm{M}\right)$ also showed no apparent affect on the autoradiographic image (data not shown) or on cytosolic protein phosphorylation as reported previously (Squinto et al., 1980).

\section{Discussion}

A nerve stump length paradigm was employed to determine whether cessation of the impulse-directed usage of skeletal muscle, or possibly other neurotrophic influences, affect the phosphorylation of soluble protein in cytosolic fractions of the slow twitch soleus muscle of the rat. As previously reported from this laboratory (Squinto et al., 1980, 1981), the in vitro phosphorylation of soluble protein catalyzed by an endogenous $\mathrm{Mg}^{2+}$ dependent $\left[\gamma^{32} \mathrm{P}\right] \mathrm{ATP}$ :phosphotransferase is increased in cytosolic fractions from denervated soleus muscles. However, this change did not occur immediately upon cutting the nerve, but after a delay of only several hours.

In this investigation, the temporal dependency of al- 


\section{DENERVATED}
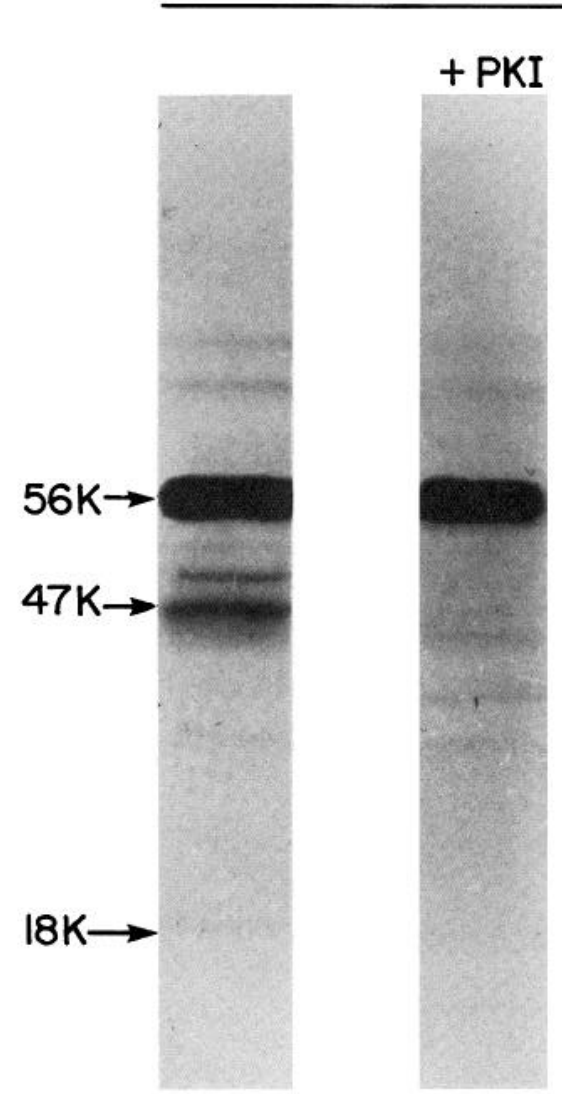
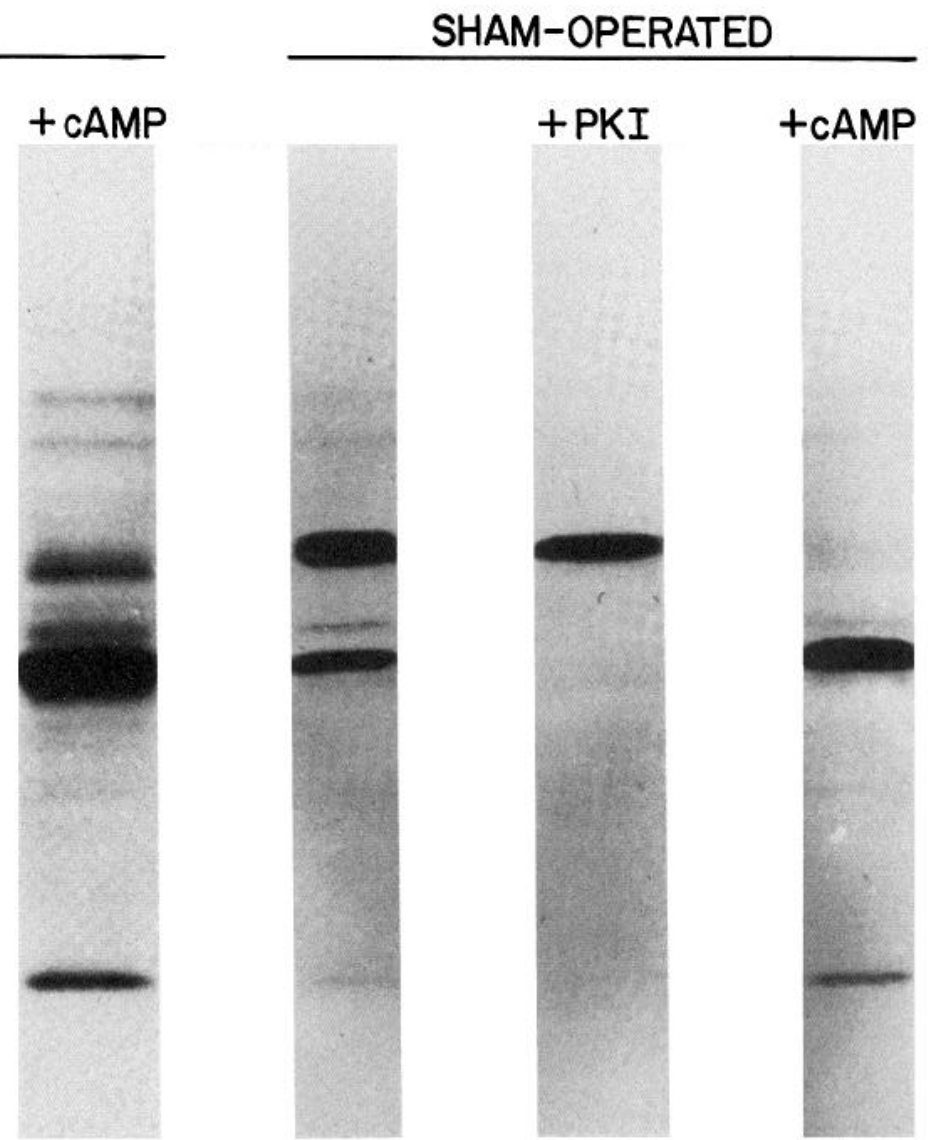

Figure 5. The effect of cAMP and the specific inhibitor of cAMP-dependent protein kinase upon the in vitro phosphorylation of the 56-kd soluble protein in denervated and sham-operated cytosolic fractions of soleus muscles. Cytosol samples from soleus muscles denervated with a short $(<2 \mathrm{~mm})$ nerve stump and the contralateral, sham-operated controls were ${ }^{32} \mathrm{P}$ radiolabeled in vitro and resolved by SDS slab PAGE. Autoradiographs of the resolved cytosolic samples from denervated and sham-operated muscles which were phosphorylated in the standard assay mixture or with the addition of 50 inhibitory units of protein kinase inhibitor $(+P K I)$ or $10^{-6} \mathrm{M}$ cAMP $(+c A M P)$ to the assay are shown. Molecular weights indicated were determined relative to the mobilities of the protein standards listed in the legend to Figure 3.

terations in the phosphorylation of soluble protein in cytosolic fractions from denervated soleus muscles was evaluated relative to three lengths of distal nerve stumps left attached to muscle. After the soleus branch of the sciatic nerve was cut to leave a short distal nerve stump of $2 \mathrm{~mm}$ or less, a significant increase in cytosolic protein phosphorylation was first observed at $3 \mathrm{hr}$. The maximal increment was reached after a denervation period of 24 $\mathrm{hr}$ and this was maintained for another $12 \mathrm{hr}$. However, this denervation effect upon protein phosphorylation was not observed at any of the early periods (i.e., 3,12 , or 24 hr) when distal nerve stumps of intermediate (17 to 20 $\mathrm{mm}$ ) or long ( 32 to $35 \mathrm{~mm}$ ) lengths were left attached to the soleus. Likewise, no change was found at 36 or $42 \mathrm{hr}$ in the long nerve stump muscle, although the onset of increased cytosolic protein phosphorylation was observed by $30 \mathrm{hr}$ in the intermediate nerve stump muscle. Cytosolic protein phosphorylation was increased significantly even when a marked weight loss occurred by 66 $\mathrm{hr}$ for the long nerve stump muscle. Therefore, muscle disuse per se, at least for a short duration of a few days, and early stages of denervation atrophy apparently do not contribute to the effect of denervation upon the phosphorylation of soluble cytosolic protein.

More precisely, the times of onset and also of maximal increase in cytosolic protein phosphorylation were both found to relate directly to the three distal nerve stump lengths. The delay in the onset of increased cytosolic protein phosphorylation was $1.4 \mathrm{hr} / \mathrm{mm}$ of nerve stump, as described in a preliminary report (McLane et al., 1981). The comparable slope ( $1.3 \mathrm{hr} / \mathrm{mm}$ of nerve stump) of the linear regression line derived from the denervation periods at which a maximal increase was observed also indicates that the rate of change in this phosphorylation event during the 21-hr mean interval from onset to peak is the same for any of the three nerve stump muscles. Establishment of a temporal dependency for the onset of biochemical and physiological alterations in the contiguous muscle cell after transections of the peripheral nerve at various distances from its insertion into the muscle is widely interpreted as evidence of a neurotrophic function (Lubinska, 1975; Grafstein and Forman, 1980). Whereas endplate potentials evoked by the impulse-directed release of $\mathrm{ACh}$ at the neuromuscular junction cease whenever the nerve is transected, axoplasmic transport has been shown to continue in isolated segments of peripheral nerve (Ochs and Ranish, 1969). However, the supply of axonally transported substances to the neuromuscular junction will be limited quantitatively and temporally by the length of the distal nerve 
stump. Speculatively, therefore, cytosolic protein phosphorylation may be modulated by a gradual depletion in the supply of an axonally transported neurotrophic factor.

Relatively few biochemical alterations in the target muscle cell which are related to the nerve stump length have been identified. Those reported include changes in the following parameters: (1) proteolytic activity (Hajek et al., 1964; McLaughlin et al., 1974), (2) endplate acetylcholinesterase activity (Davey and Younkin, 1978; Ranish et al., 1980), (3) phosphatidylethanolamine (Fernandez et al., 1979), (4) RNA synthesis (Politoff and Blitz, 1978), (5) cAMP concentration (Carlsen, 1975), and (6) glucose-6-phosphate dehydrogenase activity (Robbins and Carlson, 1979; Wagner and Max, 1979; Robbins, 1981). This last enzyme change, however, reportedly does not occur in rat soleus muscle (Wagner and Max, 1979). Before changes in the other above parameters were seen, a much longer latent period of 12 to $72 \mathrm{hr}$ was observed compared to the early onset of increased protein phosphorylation which we find at $3 \mathrm{hr}$. To our knowledge, a denervation period and nerve stump length-dependent change in the phosphorylation of soluble cytosolic muscle protein has not been described previously.

Changes in electrophysiological properties of the muscle membrane which have been related to the nerve stump length include the following: (1) the decrease in muscle resting membrane potential (Deshpande et al., 1976; Card, 1977; Boegman et al., 1980; Stanley and Drachman, 1980), (2) the appearance of extrajunctional ACh receptors (Luco and Eyzaguirre, 1955; Emmelin and Malm, 1965; Uchitel and Robbins, 1978; Stanley and Drachman, 1980), (3) a change in the spontaneous release of ACh (Luco and Eyzaguirre, 1955; Miledi and Slater, 1970; Card, 1977), and (4) the appearance of tetrodotoxin-resistant action potentials (Harris and Thesleff, 1972). During the period of functional failure, nerve stump-related ultrastructural degeneration of the axonal terminals has been reported (Miledi and Slater, 1970; Manolov, 1974; Card, 1977; Pulliam and April, $1979 \mathrm{a}, \mathrm{b})$, but apparently these are not responsible for the onset of the electrophysiological alterations (Tiedt et al., 1977; Bray et al., 1979; Guth and Albuquerque, 1979; Guth et al., 1980; Oh et al., 1980). Fibrillatory activity has been reported to occur at 42 and $48 \mathrm{hr}$ after the sciatic nerve is sectioned $5 \mathrm{~mm}$ or $30 \mathrm{~mm}$, respectively, from its insertion into the soleus muscle of the rat (Salafsky et al., 1968). Therefore, the early onset of increased phosphorylation of cytosolic protein which we found at $3 \mathrm{hr}$ and $30 \mathrm{hr}$ for the short and intermediate nerve stump solei, if not at $48 \mathrm{hr}$ for the long nerve stump-muscle, apparently precedes the development of fibrillation potentials.

It was reported recently that the neurotrophic regulation of the muscle resting membrane potential and extrajunctional $\mathrm{ACh}$ receptors may be mediated by spontaneous ACh transmission (Drachman et al., 1982). This was based upon finding that the quantitative changes in the resting membrane potential and numbers of extrajunctional $\mathrm{ACh}$ receptors were equivalent when all $\mathrm{ACh}$ receptors were specifically blocked with $\alpha$-bungarotoxin or when the soleus muscle of the rat was surgically denervated. However, blockage of impulse-directed release of $\mathrm{ACh}$ with tetrodotoxin also produced a change in these parameters, but which was quantitatively less than that induced by surgical denervation. Presently, however, it is not known whether any other nerve stump length-dependent events in skeletal muscle may be related solely to some change in the spontaneous quantal or nonquantal release of $\mathrm{ACh}$. Regarding the neuroregulation of the cytosolic protein phosphorylation, again it is significant to evaluate temporal relationships closely. Other investigators have reported that the spontaneous, quantal release of $\mathrm{ACh}$ as measured in vivo by the production of miniature endplate potentials will continue for 12 to $14 \mathrm{hr}$ in short nerve stump-solei before ceasing (Deshpande et al., 1976; Stanley and Drachman, 1980). The nonquantal form of spontaneous ACh release may cease within a few hours in a short nerve stump muscle (Stanley and Drachman, 1981). A significant increase of cytosolic protein phosphorylation in our short nerve stump-solei occurred as early as $3 \mathrm{hr}$, reached a peak at $24 \mathrm{hr}$, and remained stimulated for another 12 hr. Whether this temporal pattern would correlate with a nerve stump-related cessation of quantal or nonquantal spontaneously released $\mathrm{ACh}$ is not clear.

During this investigation, our evaluation of the substrates of the nerve stump-related phosphorylation reaction involved the resolution of the in vitro ${ }^{32} \mathrm{P}$-phosphorylated soluble proteins of the soleus cytosol by SDS slab PAGE and their detection by autoradiography. Radiolabeled phosphate apparently was incorporated into proteins resolved after electrophoresis in 10 of the 45 stained gel bands. However, quantitative evaluation of the effect of denervation upon protein phosphorylation was feasible for only one lightly stained, minor band of protein having a relative $M_{\mathrm{r}}$ of 56,000 which contained $\sim 80 \%$ of the ${ }^{32} \mathrm{P}$ labeling. This protein was previously described by us (Squinto et al., 1981) as having a $M_{\mathrm{r}}$ of $\sim 40,000$ in a SDS rod PAGE system. The apparent discrepancy has been resolved by determining that the $M_{\mathrm{r}}$ of the ${ }^{32} \mathrm{P}$-labeled, $40-\mathrm{kd}$ gel band after re-electrophoresis and improved resolution in the SDS slab PAGE system is 56,000. This molecular weight and the localization of this substrate in the soluble fraction of the cytosol rule out a number of phosphorylatable cytosolic substrates in skeletal muscle which are usually associated with mitochondria, myofibrils, or glycogen particles. Fven if trace amounts of certain particulate phosphoproteins should be present, the $M_{\mathrm{r}}$ of their subunits are either considerably lower or higher than 56,000 . The phosphorylated light chains of myosin have $M_{\mathrm{r}}$ less than 29,000; subunits of myosin light chain kinase, glycogen phosphorylase, phosphorylase kinase, glycogen synthetase, and phosphofructokinase have $M_{\mathrm{r}}$ greater than 75,000 (Weller, 1979; Stull, 1980). It is also pertinent to note that early denervation effects apparently are not energy related, since decreased activities of glycogen phosphorylase and glycogen synthetase and reduced levels of ATP have not been observed in rat soleus muscles before 5 or 9 days, respectively, after denervation (Hogan et al., 1965; Kauffman and Albuquerque, 1970; Pichey and Smith, 1979).

Our results, reported here, and preliminary findings presented elsewhere (McLane et al., 1982) suggest that 
the neurotrophic-related, 56-kd phosphoprotein is the regulatory subunit of the soluble cAMP-dependent protein kinase type II (R-II). The relative $M_{\mathrm{r}}$ of $\mathrm{R}$-II by SDS slab PAGE is also 56,000 (Zoller et al., 1979; RangelAldao et al., 1979). R-II is phosphorylated in vitro and in vivo by an autophosphorylation reaction in which the catalytic subunit of the soluble holoenzyme catalyzes the transfer of the terminal phosphate of ATP to a unique seryl residue (Erlichman et al., 1974; Hoffman et al., 1975; Rangel-Aldao and Rosen, 1977; Geahlen et al., 1982). The marked reduction in the phosphorylation of the 56-kd band resolved by SDS slab PAGE which we observed when cAMP was added to the in vitro assay is consistent with the expected inhibitory effect of cAMP upon the autophosphorylation of R-II caused by the dissociation of the regulatory and catalytic subunits. Additionally, when a specific inhibitor of the free catalytic subunit of cAMP-dependent protein kinase (Ashby and Walsh, 1972) was added to the assay, no apparent change in the phosphorylation of the $56-\mathrm{kd}$ band was observed as would be expected for an intramolecular autophosphorylation of R-II. Although it is already well established that the physiologic actions of some neurotransmitters and hormones are mediated by cAMP-dependent protein kinases (Greengard, 1978), the physiologic significance of the autophosphorylation of $\mathrm{R}-\mathrm{II}$ is not known.

The subunits of other soluble protein kinases which are dissociated from the holoenzyme upon binding cAMP or cGMP are not likely to be the $56-\mathrm{kd}$ substrate of the neuroregulated protein kinase reaction. The phosphorylated catalytic subunits of cAMP-dependent protein kinase types I and II have $M_{\mathrm{r}}$ of only 40,000 (Sharma, 1982) and were ruled out by previous studies from this laboratory (Squinto et al., 1981). The $M_{\mathrm{r}}$ of the phosphorylatable regulatory subunit of the type I enzyme is 49,000 (Geahlen and Krebs, 1980; Sharma, 1982). The autophosphorylatable subunits of cGMP-dependent protein kinases have $M_{\mathrm{r}}$ of 75,000 .

It is not known how neurotrophic messages which may be supplied by spontaneously released $\mathrm{ACh}$ or axonally transported factors are translated by muscle cells into biological responses. Slab PAGE autoradiographs of in vitro ${ }^{32} \mathrm{P}$-labeled cytosols from short, intermediate, and long nerve stump muscles which had maximal increases in cytosolic protein phosphorylation showed that this change is consistently and predominantly associated with the major phosphorylatable soluble protein of 56 $\mathrm{kd}$. Also, the increase of the cytosolic protein phosphorylation during the stimulatory period could be accounted for by increases in the ${ }^{32} \mathrm{P}$ labeling of the $56-\mathrm{kd}$ protein. The denervation period and nerve stump length-related increase in phosphorylation of a cAMP-modulated, 56$\mathrm{kd}$ soluble protein in cytosolic fractions of skeletal muscle, tentatively identified as R-II, offers new insight into non-impulse-mediated interactions between nerve and muscle which we will continue to explore with other animal models.

\section{References}

Ashby, C. D., and D. A. Walsh (1972) Characterization of the interaction of a protein inhibitor with adenosine $3^{\prime}, 5^{\prime}$-mon- ophosphate-dependent protein kinases. J. Biol. Chem. 20: 6637-6642.

Boegman, R. J., S. S. Deshpande, and E. X. Albuquerque (1980) Consequences of axonal transport blockade induced by batrachotoxin on mammalian neuromuscular junction. I. Early pre- and postsynaptic changes. Brain Res. 187: 183196.

Bray, J. J., J. I. Hubbard, and R. G. Mills (1979) The trophic influence of tetrodotoxin-inactive nerves on normal and reinnervated rat skeletal muscles. J. Physiol. (Lond.) 297: 479491.

Buller, A. J., J. C. Eccles, and R. M. Eccles (1960) Interactions between motoneurons and muscles in respect of the characteristic speeds of their responses. J. Physiol. (Lond.) 150: 417-439.

Card, D. J. (1977) Denervation: Sequence of neuromuscular degenerative changes in rats and the effect of stimulation. Exp. Neurol. 54: 251-265.

Carlsen, R. C. (1975) The possible role of cyclic AMP in the neurotrophic control of skeletal muscle. J. Physiol. (Lond.) 247: 343-361.

Close, R. I. (1972) Dynamic properties of mammalian skeletal muscles. Physiol. Rev. 52: 129-197.

Davey, B., and S. G. Younkin (1978) Effect of nerve stump length on cholinesterase in denervated rat diaphragm. Exp. Neurol. 59: 168-175.

Deshpande, S. S., E. X. Albuquerque, and L. Guth (1976) Neurotrophic regulation of prejunctional and postjunctional membrane at the mammalian motor endplate. Exp. Neurol. 53: $151-165$.

Drachman, D. B., E. F. Stanley, A. Pestronk, J. W. Griffin, and D. L. Price (1982) Neurotrophic regulation of two properties of skeletal muscle by impulse-dependent and spontaneous acetylcholine transmission. J. Neurosci. 2: 232-243.

Emmelin, N., and L. Malm (1965) Developinent of supersensitivity as dependent on the length of degenerating nerve fibers. Q. J. Exp. Physiol. 50: 142-145.

Erlichman, J., R. Rosenfeld, and O. M. Rosen (1974) Phosphorylation of a cyclic adenosine $3^{\prime}: 5^{\prime}$-monophosphate-dependent protein kinase from bovine cardiac muscle. J. Biol. Chem. 249: 5000-5003.

Fernandez, H. L., R. V. Dorman, and B. W. Festoff (1979) Neurotrophic control of skeletal muscle phospholipids. Muscle Nerve 2: 118-123.

Geahlen, R. L., and E. G. Krebs (1980) Regulatory subunit of the type I cAMP-dependent protein kinase as an inhibitor and substrate of the cGMP-dependent protein kinase. J. Biol. Chem. 255: 1164-1169.

Geahlen, R. L., D. F. Carmichael, E. Hashimoto, and E. G. Krebs (1982) Phosphorylation of cAMP-dcpendent protein kinase subunits. Adv. Enzyme Regul. 20: 195-209.

Grafstein, B., and K. S. Forman (1980) Intracellular transport in neurons. Physiol. Rev. 80: 1167-1283.

Greengard, P. (1978) Phosphorylated proteins as physiological effectors. Science 199: 146-152.

Guth, L., and E. X. Alburqueque (1979) The neurotrophic regulation of resting membrane potential and extrajunctional acetylcholine sensitivity in mammalian skeletal muscle. In Muscle Regeneration, A. Mauro, ed., pp. 405-415, Raven Press, New York.

Guth, L., E. Richman, C. Barrett, J. E. Warnick, and E. X. Albuquerque (1980) The mechanisms by which degenerating peripheral nerve produces extrajunctional acetylcholine sensitivity in mammalian skeletal muscle. Exp. Neurol. 68: 465476.

Gutmann, E. (1976) Neurotrophic relations. Annu. Rev. Physiol. 38: 177-216.

Hajek, I., E. Gutmann, and I. Srovy (1964) Proteolytic activity in denervated and reinnervated muscle. Physiol. Bohemoslov. 13: $32-38$. 
Harris, A. J. (1974) Inductive functions of the nervous system. Annu. Rev. Physiol. 36: 251-305.

Harris, A. J. (1980) Trophic effects of the nerve on muscle. In The Physiology of Peripheral Nerve Disease, A. J. Sumner, ed., pp. 195-220, W. B. Saunders Co., Philadelphia.

Harris, J. B., and S. Thesleff (1972) Nerve stump length and membrane changes in denervated skeletal muscle. Nature New Biol. 236: 60-61.

Held, I. R. (1978) Stimulation of nuclear RNA synthesis in denervated skeletal muscles. J. Neurochem. 30: 1239-1243.

Held, I. R. (1983) Increased phosphorylation of nuclear protein in myonuclei isolated from denervated skeletal muscle. J. Neurosci. Res. 9: 203-210.

Hoffman, F., J. A. Beavo, P. J. Bechtel, and E. G. Krebs (1975) Reversible autophosphorylation of a cyclic $3^{\prime}: 5^{\prime}$-cAMP-dependent protein kinase from bovine cardiac muscle. J. Biol. Chem. 250: 7795-7801.

Hogan, E. L., D. M. Dawson, and F. A. Romanul (1965) Enzymatic changes in denervated muscles. II. Biochemical studies. Arch. Neurol. 13: 274-282.

Kanter, J. R., and L. L. Brunton (1981) Cautions on the use of the heat stable inhibitor of protein kinase: Studies with $\mathbf{\$} 49$ lymphoma cells. J. Cyclic Nucleotide Res. 7: 259-268.

Kauffman, F. C., and E. X. Albuquerque (1970) Effect of ischemia and denervation on metabolism of fast and slow mammalian skeletal muscle. Exp. Neurol. 28: 46-63.

Laemmli, U. K. (1970) Cleavage of structural proteins during the assembly of the head of basteriophage $\mathrm{T}_{4}$. Nature 227: $680-685$.

Lowry, O. H., N. J. Rosebrough, A. L. Farr, and R. J. Randall (1951) Protein measurement with the Folin phenol reagent. J. Biol. Chem. 193: 265-275.

Lubinska, L. (1975) On axoplasmic flow. Int. Rev. Neurobiol. 17: 241-296.

Luco, J. V., and C. Eyzaguirre (1955) Fibrillation and hypersensitivity to $\mathrm{ACH}$ in denervated muscle: Effect of length of degenerating nerve fibers. J. Neurophysiol. 18: 65-73.

Manolov, S. (1974) Initial changes in the neuromuscular synapses of denervated rat diaphragm. Brain Res. 65: 303-316.

McLane, J. A., S. P. Squinto, H. C. Yeoh, and I. R. Held (1981) Neurotrophic regulation of cytosolic phosphorylating activity in muscle. Trans. Am. Soc. Neurochem. 12: 230.

McLane, J. A., S. P. Squinto, and I. R. Held (1982) Resolution of the denervation-dependent phosphopolypeptide in rat skeletal muscle cytosol. Soc. Neurosci. Abstr. 8: 184.

McLaughlin, J., L. G. Abood, and H. B. Bosmann (1974) Early elevations of glycosidase, acid phosphatase and acid proteolytic enzyme activity in denervated skeletal muscle. Exp. Neurol. 42: 541-554.

Miledi, R., and C. R. Slater (1970) On the degeneration of rat neuromuscular junctions after nerve section. J. Physiol. (Lond.) 207: 507-528.

Ochs, S. (1974) Systems of material transport in nerve fibers (axoplasmic transport) related to nerve function and trophic control. Ann. N. Y. Acad. Sci. 228: 202-223.

Ochs, S., and N. Ranish (1969) Characteristics of the fast transport system in mammalian nerve fibers. J. Neurobiol. 1: $247-261$.

Oh, T. H., G. J. Markelonis, P. J. Reier, and A. A. Zalewski (1980) Persistence in degenerating sciatic nerve of substances having a trophic influence upon cultured muscle. Exp. Neurol. 67: $646 \cdot 654$.

Pichey, E. L., and P. B. Smith (1979) Denervation and developmental alterations of glycogen synthase and glycogen phosphorylase in mammalian skeletal muscle. Exp. Neurol. 65: $118-130$.

Politoff, A. L., and A. L. Blitz (1978) Neurotrophic control of RNA synthesis in amphibian striated muscles. Brain Res.
151: $561-570$.

Pulliam, D. L., and E. W. April (1979a) Degenerative changes at the neuromuscular junctions of red, white and intermediate muscle fibers. I. Response to short stump nerve section. J. Neurol. Sci. 43: 205-222.

Pulliam, D. L., and E. W. April (1979b) Degenerative changes at the neuromuscular junctions of red, white and intermediate muscle fibers. II. Responses to long stump nerve section and colchicine treatment. J. Neurol. Sci. 43: 223-241.

Rangel-Aldao, R., and O. M. Rosen (1977) Effect of cAMP and ATP on the reassociation of phosphorylated and nonphosphorylated subunits of the cAMP-dependent protein kinase from bovine cardiac muscle. J. Biol. Chem. 252: 7140-7145.

Rangel-Aldao, R., J. W. Kupicc, and O. M. Rosen (1979) Resolution of the phosphorylated and dephosphorylated cAMP-binding proteins of bovine cardiac muscle by affinity labeling and two-dimensional electrophoresis. J. Biol. Chem. 254: 2499-2508.

Ranish, N. A., W. D. Dettbarn, and L. Wecker (1980) Nerve stump length-dependent loss of acetylcholinesterase activity in endplate regions of rat diaphragm. Brain Res. 191: 379386.

Robbins, N. (1981) Neurotrophic regulation of rat muscle glucose-6-phosphate dehydrogenase in vitro. Brain Res. 225: 387-399.

Robbins, N., and D. Carlson (1979) Early changes in muscle glucose-6-phosphate dehydrogenase activity after denervation: Locus and dependence on nerve stump length. Brain Res. 177: 145-156.

Salafsky, B., J. Bell, and M. A. Prewitt (1968) Development of fibrillation potentials in denervated fast and slow skeletal muscle. Am. J. Physiol. 215: 637-643.

Sharma, R. K. (1982) Cyclic nucleotide control of protein kinases. Prog. Nucleic Acid Res. Mol. Biol. 27: 233-288.

Squinto, S. P., J. A. McLane, and I. R. Held (1980) Effect of denervation on the endogenous phosphorylating activity in the cytosol of rat skeletal muscle. Neurosci. Lett. 20: 295300 .

Squinto, S. P., J. A. McLane, and I. R. Held (1981) Increased phosphorylation in vitro of a cytosolic polypeptide resolved from denervated skeletal muscle. Neurochem. Res. 6: 203211.

Stanley, E. F., and D. B. Drachman (1980) Denervation and the time course of resting membrane potential changes in skeletal muscle in vitro. Exp. Neurol. 69: 253-259.

Stanley, E. F., and D. B. Drachman (1981) Non-quantal ACh release in the mouse diaphragm: Effects of denervation and botulinum toxin. Soc. Neurosci. Abstr. 7: 440.

Stull, J. T. (1980) Phosphorylation of contractile proteins in relation to muscle function. Adv. Cyclic Nucleotide Res. 13: 39-93.

Teidt, T. N., E. X. Albuquerque, and L. Guth (1977) Degenerating nerve fiber products do not alter physiological properties of adjacent innervated skeletal muscle fibers. Science 198: 839-841.

Uchitel, O., and N. Robbins (1978) On the appearance of acetylcholine receptors in denervated rat diaphragm, and its dependence on nerve stump length. Brain Res. 153: 539-548.

Wagner, K. R., and S. R. Max (1979) Neurotrophic regulation of glucose-6-phosphate dehydrogenase in rat skeletal muscle. Brain Res. 170: 572-576.

Weller, M. (1979) Protein Phosphorylation: The Nature, Function, and Metabolism of Proteins which Contain Covalently Bound Phosphorus, pp. 163-220, 416-421, 452-453, Methuen, Inc., New York.

Zoller, M. J., A. R. Kerlavage, and S. S. Taylor (1979) Structural comparisons of cAMP-dependent protein kinases I and II from porcine skeletal muscle. J. Biol. Chem. 254: 2408-2412. 